\title{
Problem and Prospect of FDI inflows in Indian Pharmaceutical Industry ${ }^{1}$
}

\author{
Dr. Gulshan Akhtar
}

\begin{abstract}
The development of Indian talent and adoption of managerial techniques by domestic firms has made India a preferred destination of FDI. This is a positive spiral of the spillover effects of FDI. Due to earlier FDI infusions the human capital has been upgraded which in turn is attracting more FDI. Hence the spillover effects are evident in increasing the productivity of the IPI and have resulted in India gaining respect as a global player. The inflow of FDI in India has experienced considerable growth but compared to other developing nations, India has lagged behind; attracts only about 2\% of FDI inflows. In order to reap the maximum benefits from FDI, there is a need to establish a transparent broad and effective enabling policy environment for investment and to put in place appropriate framework for their implementation. It has been noticed that there has been ample opportunity for the concentration of FDI in the sector particularly export and profitability of the sector
\end{abstract}

Keywords: FDI; Pharmaceuticals Industry; MNCs; DMFs; ANDAs; CAGR.

\section{Introduction:}

The sweeping changes introduced since 1991 mark a radical departure from the past and reflect a positive approach towards foreign investment. The changes provide freedom to foreign investors to enter the Indian economy. In terms of openness to FDI (Foreign Direct Investment) entry, the prevailing Indian policy is favourably placed in terms of competitiveness with other major FDI receiving countries in Asia. The inflow of FDI in India has experienced considerable growth but compared to other developing nations, India has lagged behind; attracts only about $2 \%$ of FDI inflows.

FDI is beneficial for our economy but its effectiveness depends upon its meaningful use and it's directing to the areas/ sectors where shortage of domestic capital investment is felt. More specifically from the development point of view FDI process is related to export oriented areas. It provides financial resources managerial expertise, technologies and entrepreneurial skills through the channel of MNCs (Multi-National Corporations). The FDI policy has to be constantly reviewed towards this end and necessary steps should be taken to make India a most favourable destination for FDI. The focus of FDI should be to maximize its contribution to India's development and welfare rather than maximizing the magnitude of inflows.

The presence of FDI in Indian Pharmaceuticals Industry (IPI) does not mean automatic positive effects. It depends on the development of the domestic firms and the endeavours of domestic firms to invest in learning and imitation. In order to reap the maximum benefits from FDI, there is a need to establish a transparent broad and effective enabling policy environment for investment and to put in place appropriate framework for their implementation. Such an environment must provides incentives for innovations and improvement of skills and contribute towards improved competitiveness. The cumulative amount of FDI inflows during August 1991 to February 2011 is US\$145249 million (DIPP, 2012).

Sector-wise break-up of FDI inflow during Post reform period revealed that the most leading sector is the services sector which received an approval share of $20.35 \%$. Computer and IT sector has also registered a good share of $8.52 \%$. Infrastructure sector including communication housing \& real estates posted a growth of $7.94 \%, 7.13 \%$ and $6.90 \%$ respectively (DIPP, 2012). However, pharmaceutical sector which was at $8^{\text {th }}$ place during 1991-2007 declined to $12^{\text {th }}$ place after 2007 mainly due to impact of the new patent law and global recession. But the position has now improved.

The largest source of FDI in India's pharmaceutical industry is Mauritius (56.4\%). Singapore is the second largest source (11.2\%) followed by the USA (5.8), UAE (4.7\%), and Canada (4\%), together they accounted for more than $80 \%$ of FDI in this sector during 2008-09. The state-wise FDI trends reveals that Maharashtra at top of the list with a percentage share of $35.24 \%$ followed by New Delhi with a share of $20.50 \%$, Karnataka (6.26\%), Gujarat (5.79\%) and Tamil Nadu (4.91\%) (DOP, 2010). Together they accounted more than $70 \%$ of the total FDI inflows during 2000-10. It is important to note that $75 \%$ of pharmaceutical manufacturing production is done by Maharashtra, Gujarat, Tamil Nadu, Andhra Pradesh, Karnataka, West Bengal and Goa.

${ }^{1}$ This article is a part of my Thesis submitted 2012 in AMU, Aligarh 
This may be attributed to their better resources, good infrastructure and investor friendly policies. It is observed that FDI inflows have positive impact on the Indian pharmaceutical industry. Although larger FDI inflows in these states have had a favourable impact on the economy and pharmaceutical sector, but it has also led to wider regional disparities.

\section{Indian Pharmaceutical Industry- At a Glance:}

Over a period of time the IPI has promoted, integrated, and induced self-sustained growth of the Indian economy. However, there is a pressing need to lift up the sector as an impetus of industrial growth and employment and to achieve a high degree of value addition in the country. It is currently recognized as 'global pharmacy' of developing world and has distinction of providing quality healthcare at affordable cost. The IPI is currently divided into three-tier structure. Large MNCs operates as originator drug companies, generic companies along with large Indian generic companies and medium and small scale industries. Pharmaceutical industry contributed nearly $12 \%$ of India's manufacturing sector GDP and around $2 \%$ of the country's GDP during 2008-09. Besides this drugs \& pharmaceuticals, have been consistently $5^{\text {th }}$ largest exported principal commodity of the country for the last several years. In terms of trade balance it is the only Indian sector after apparels that have consistently given positive trade balance and it growing around 1.5-1.6 times of country GDP growth rate. Furthermore it is a net earner of foreign exchange and this kept increasing throughout the years since 1991. Its turnover also witnessed a tremendous growth over the past few years i.e. from US\$2857.14 million in 1990-91 to US\$20787.40 million in 2009-10 i.e. raised more than seven-folds. From simple headache pills to sophisticated antibiotics and complex cardiac compounds, almost every type of medicine is now made indigenously.

At the global arena IPI ranks very high and is placed third in the world in terms of technology, quality and range of medicines manufactured. The country now ranks third world-wide by volume of production also and $14^{\text {th }}$ by value of production. Globally it ranks $4^{\text {th }}$ in terms of generic production and $3^{\text {rd }}$ largest bulk drugs producers in the world. It ranks $17^{\text {th }}$ in terms of export value of bulk drugs \& formulations. India account for over one-third of DMFs (Drugs Master Files) in USA and 30\% of all approved ANDAs (Abbreviated New Drug Applications) in the US. Even in patent challenges India ranks $2^{\text {nd }}$ only next to USA with a share of $21 \%$ of patent challenges.

The 1990s witnessed the strongest performance of the IPI on several fronts, not only did the industry exceed its output expansion of the previous decades but became a net foreign exchange earner. This performance followed the changes in the policy orientation of the Indian economy that took place in 1991. Industry thus took advantages of the unshackling of the industrial sector during the 1990s from the controls imposed by the government. The rapid opening up of what had been largely an insulated economy to international trade and investment brought about a swift response from the leading firms in the pharmaceutical industry.

The production of bulk drugs rose from US\$396.5 million in 1991 to US\$3503.2 million in 2008 showing a CAGR of $14.4 \%$ during 2006-08. The production of formulation on the other hand increased from US\$2114.5 million to US\$ 15390.8 million during the same period of time with CAGR of $23.6 \%$. A noteworthy feature of the analysis is that during 2005-08 the CAGR of bulk drugs production was nearly half as compared to the growth rate of formulations production. It is indicated that formulation production increases at a faster rate as compared to the bulk drugs production. This reveals that IPI is shifting from the production and trading of bulk drugs to formulations during post-reform period.

Similarly the export performance of the pharmaceutical industry is also very remarkable given that it has been the only amongst the major industrial sector to have consistently generated trade surplus irrespective to global crisis. Indian pharmaceutical export increased from US\$ 564.4 million in 1991 to US\$ 6257.0 million in 2008. Trade balance also increased US\$ 320.1 million to US\$4286.5 million during the same period of time. As a result this sector contributes nearly $5 \%$ of India's total manufactured exports. India's share in world pharmaceutical export also improved from $0.9 \%$ in 1992 to $1.4 \%$ in the year 2008 .

The pharmaceutical industry is severely technological and capital intensive and India is one of the very few developing countries that have comparative advantages in the industry. However despite the impressive growth of this sector and low costs production there are several concerns which needs to be addressed. Like accessibility and affordability of medicines by the common man, instituting standards of quality, strengthening the fragmented regulatory system, sustaining growth of generic etc.

The IPI responded to economic reforms in many different ways. Firms like Cipla, Zydus and Lupin etc improved their manufacturing efficiency and established large production facilities. While firms like Sun pharma, Torrent and Wockhdardt etc re-structured and shifted their technology focus, product basket and market focus. Special emphasis was given to marketing and distribution networks by almost all leading firms during this time. Besides, domestic leaders substantially increased their in-house R\&D investment and implemented new approaches of drug/product development. 


\section{Inflows of FDI in Indian Pharmaceutical Sector:}

FDI inflow in Indian pharmaceutical was only US $\$ 0.3$ million in 1991 and reach highest US\$334.1 million in 2007; thereafter it declined to US\$181.5 million in 2008 i.e. 605 times of the figure of 1991. The growth rates indicates considerable fluctuations both in positive and negative rates and highest was in 1992 (3600\%) (DOP, 2009). The share of pharmaceutical industry FDI in total FDI was $2.05 \%$ on an average. The inflow in pharmaceutical takes the mean of US\$94.3 million and SD (Standard Deviation) of US\$100.9 million. The fluctuation is demonstrated by the CV (Coefficient of Variation) of 1.07. The growth rate is $27 \%$ during 1991-2008. One of the reasons behind such high growth rate is the big difference between the minimum and maximum value of FDI inflows in pharmaceutical industry.

The pharmaceutical investment was US\$ 38.4 million in 1991 it gradually increased to US\$4117.1million in 2008, i.e. almost 107 times of the figure of 1991. The inflow of FDI in Pharmaceutical sector was only US\$0.3 million in 1991 and increased to US\$ 181.5 million in 2008 (CMIE, 2010). The share of FDI in total investment of pharmaceutical industry was $11.8 \%$ on an average. The mean of pharmaceutical industry investment is US\$1027.4 million with SD of US\$ 1282.5 million. The mean of the FDI inflows in the pharmaceutical industry is US\$ 94.3 million with a SD of US\$ 100.9 million. The t-ratio is statistically significant at $10 \%$ level. The CV is 1.24 in case of the investment in pharmaceutical industry and 1.07 in case of the FDI inflows to demonstrate the unstable nature of FDI inflows in the industry.

The total pharmaceutical production figures indicate that in 1991 the figure was US $\$ 2510.6$ million, where as it increased to US\$17567.6 million in 2008 which is seven times higher than that of the 1991(CMIE, 2010). The mean of the variable is US\$6868.4 million and the SD is US\$ 4463.5 million. The t-ratio is 6.01 suggesting that the mean is statistically significant at $10 \%$ level. The variable is considerably stable as is demonstrated by a comparatively low coefficient of variance of 0.65 .

In 1991 the export of the industry was only US\$564.4million and through a gradual increase it took the amount of US\$6257 million in 2008, which is nearly eleven times that of the 1991 figure (CMIE, 2010). The average takes a value of US\$ 1862.2 million. The SD is however quite impressive at an amount of US\$ 1758.7 million. The t-ratio is 5.84 to indicate that the mean is statistically significant at $10 \%$ level. The CV is equally high at 0.94 suggesting that the estimate observes the fair extent of instability.

The amount of earned profit plays a key role in attracting the FDI inflows. It can be observed that the profit in pharmaceutical sector increased throughout the period under consideration, whereas in 1991 it was only US $\$ 14.1$ million but by 2008 it reached to a level of US\$1356 million (CMIE, 2010). The increase is around ninety-six times. One of the reasons attributed to this is that the number of firms has also increased during the period. However, it is indicated that during 1995 to 1997 the profit trend was declining. The industry faced a stiff competition during the late nineties backed by regional as well as global recession in the same year of that must have contributed to the adversities in the profit performance. Input prices also increased globally during that period coupled with high market campaigning expenses. The mean profit is US\$ 577.5 million with the SD 587.6 million. The t-ratio is 7.32 which indicate that the mean is statistically significant at $10 \%$ level. The CV is as high as 1.02 which indicates instability in the nature of the variable.

\section{Strategies and Implication for FDI in Indian Pharmaceutical Industry:}

The presence of foreign firms boosts the competitive environment in the pharmaceutical sector and spillover effects are generated through the elimination of insufficient firms and faster adoption of technology. It will be further increased in near future due to TRIPs (Trade-Related aspects of Intellectual Property Rights) implementation. Besides the MNCs invest a lot in training and positive externalities in the form of human capital development seem to be generated. Further, the MNCs are highly aware of quality standards for products and production processes which seem to have positive impact to the domestic industry to improve their products quality, continually in the future due to new patent law and enhanced investment climate. Currently, domestic firms have invested more in $R \& D$ than they did in pre-reform period and this competition in terms of R\&D can stimulate further competition and growth in the industry.

Therefore the impact of FDI on IPI manifolds. With the advent of new WTO patent regime the foreign players have found greater security in operating in the India. Due to the spillover effects of a competitive environment the domestic players have substantially increased their productivity, profitability and are on stronger footing with the incoming pharmaceutical firms. In facts domestic players have started challenging MNCs in their own country.

The development of Indian talent and adoption of managerial techniques by domestic firms has made India a preferred destination of FDI. This is a positive spiral of the spillover effects of FDI. Due to earlier FDI infusions the human capital has been upgraded which in turn is attracting more FDI. Hence the spillover effects are evident in increasing the productivity of the IPI and have resulted in India gaining respect as a global player.

FDI in the IPI is mainly market-seeking. India's advantage for MNCs in the pharmaceutical industry is first of all the large domestic market, with a more than one billion population. Wide disease pattern, relatively 
cheap manpower and skilled labour are other factors that attract foreign investors. English is widely spoken language, which makes communication easy for foreign investors. The production of pharmaceuticals is also relatively cheap in India as there is a strong production base in the country. It is easy to get good quality bulk drugs, which is attractive for foreign firms. Because of India's focus on reverse engineering and the development of production processes, it has high technical competence in production in the pharmaceutical industry, which makes this industry attractive to foreign investors. The industry is also highly competitive among suppliers which give the MNCs a good bargaining position. India has many advantages for foreign investors and consequently the country has future potential to become an attractive destination for out-sourcing in drugs discovery and clinical trials.

The FDI inflow in India in absolute figure is quite impressive, but when compared to global flows, it is far from satisfaction. Thus, India at the moment needs a well-balanced strategy for enhanced FDI inflows in pharmaceutical sector. The following measures to attract FDI in India:-

> In order to promote FDI and maximize further spillover effects, polices should be investor friendly, with a clear developing strategy. The policies in India should encourage domestic firms to invest more in R\&D and technology up-gradation and human resources by providing suitable fiscal and financial incentives.

$>$ SMEs (Small and Medium Enterprises) contribute $42 \%$ of total pharmaceutical production and $62 \%$ of total employment. Government should ensure that the SSI grows at a healthy rate as it is employment intensive sector. Lack of awareness in the area of patenting of technology, GMP (Good Manufacturing Practice) and GCP (Good Clinical Practice) is an issue with SMEs. Government with the help of BDMA (Bulk Drug Manufacturers Association) and IDMA (Indian Drug Manufacturers Association) can conduct awareness camps for SMEs. This will not only help these units to match the expectations of developed market but also help in retaining or bringing back our talent abroad as specialists in this area. Further, schemes to promote compliance of schedule $\mathrm{M}$, improvement in quality by adopting international regulatory standards and technology upgradation with special focus on the SSIs. Currently, corporate players in this sector including the MNCs whose costs are prohibitively high are looking at the pharmaceutical SMEs in India to out-source their production and research programmes. This has opened up a big opportunity for SMEs pharmaceutical. But they face one major impediment in grabbing this opportunity. Their research facilities do not match with the western standards, although their manufacturing capabilities are excellent. Indian SMEs are finding it difficult to keep up with the pace of R\&D in technologically advanced countries. The prime reason for the Indian SMEs lagging behind the developed countries is the severe shortage of fund they are facing. To overcome this problem, the Indian SMEs pharmaceutical can adopt the CRAMS (Contract Research and Manufacturing Services) practice. This time-tested business is practiced elsewhere in the world and can provide a highly effective financial boost to SMEs in India.

$>$ Since R\&D in pharmaceutical is a highly risky venture, there is dire need to give incentive through tax concession on a permanent basis. It is suggested that the tax holidays should be at least 20-25 years because the development of any molecule takes at least 15-20 years.

$>$ The level of FDI in an industry is an important factor for possible spillover effects. When the level of FDI is relatively low in an industry it can lead in insignificant result. This is also the case in the IPI. This should be enhanced by providing more investor friendly policies.

> Government at various levels should take active part in disseminating knowledge about the IPRs (Intellectual Property Rights) and the possible strategies that can be adopted by the industry. Lesson should be drawn from the Chinese experience where systematic efforts were taken to educate the bureaucrats, policy makers and the industry about the WTO and product patent in pharmaceutical industry. India will have to strengthen the patent examination process and speed up the processing procedures.

$>$ Emphasize also has to be given to the macroeconomic policies, such as the monetary policy, fiscal policy, foreign trade policy, the exchange rate policy and FDI policy so that they are in tune with the requirement of the growth of the pharmaceutical sector.

> With India emerging as a major hub for Contract Research particularly clinical trials it is important to ensure good clinical practices in the country.

$>$ Animal testing is essential in drug discovery. Effective solution is needed for undertaking NCEs (New Chemical Entities) based discovery research to solve the difficulties encountered in conducting toxicity studies in bigger animals. The approval process for animal imports, animal experiment protocol, needs to be streamlined and expedited.

$>$ Spurious drugs are a sensitive issue affecting not only the level of FDI but also health of the people as well as the prestige of the country's pharmaceutical trade interest. Steps should be taken by the government to counter threat of spurious drugs.

Price regulation is another major impediment for FDI inflows in Indian pharmaceutical sector. Focus on price monitoring rather price control is required. Apart from this resolution of data exclusivity law will help in increasing confidence among foreign companies. 
> It may be noted that reforms are required at regulatory/policy level too. Presently both central and state governments regulate pharmaceutical sector. While states regulatory authorities are responsible for regulating manufacturing, sales and distribution of drugs, the central regulation approves new drugs, clinical trials, control imports of drugs and also coordinates among the states bodies. Hence, drug regulation and price control should be with the same agency so that an integrated regulatory system exists in the economy. Strengthening the regulatory system is also required in the context of new patent regime. There is a need to simplify procedures and shorten the time line for various approvals. Strengthening of regulatory system with respect to data protection is also crucial. These measures will help in attracting more FDI particularly in R\&D in India.

Technological cooperation with the MNCs stimulates growth in the manufacturing and R\&D spaces of the domestic industry. Recently, with the fear, if MNCs take over Indian companies it will lead to an oligopolistic market situation and increasing drug price (However various studies have shown that drug prices almost stable). Due to this now FDI upto $100 \%$ in Greenfield projects will remain under automatic route but in the Brownfield projects it will need to go via government approval route. The same approval which is presently done the FIPB (Foreign Investment Promotion Board) but in future it will be by the CCI (Competition Commission of India). Movement to restrict FDI in this way will a retrogressive step in the financial reform process in the country, adversely affecting FDI not only in the pharmaceutical sector but possibly far beyond it.

\section{Conclusion:}

FDI is often seen as a catalyst of Indian pharmaceutical industry. As FDI comes with financial and managerial resources, access to large markets, technical assistance and strategic assets, such as brand name, which give the host firms domestic and international comparative advantages. It has been noticed that there has been ample opportunity for the concentration of FDI in the sector particularly export and profitability of the sector.

The rate of return in the sector during 1991-2008 observed a tremendous increase. The classical theory suggests that FDI seeks high returns. Based on that theory, there should be an influx of foreign investment in Indian pharmaceutical sector. But there has been limited statistical observation in support of this view. This indicates that structural constraints still play a crucial role in the inflow of FDI in India. The economy is yet to create the investment climate required for the increased inflow of the FDI. Besides, it has been noticed by empirical studies, that most of the variables (Pharmaceutical investment, production total production exports and profit) of the pharmaceutical sector are not functionally related with the FDI inflow in the pharmaceutical sector. However, FDI inflow in the pharmaceutical sector is attracted because of high rate of return. All these evidence indicated the imperfections of the market that must be the greatest hindrance of India shining to shine in the global arena.

\section{References:}

[1] Akhtar, Gulshan (2012). "Inflows of FDI in India since 1991: A case study on Pharmaceutical Industry", Department of Economics, AMU, Aligarh, (unpublished thesis).

[2] Bergman, Annika (2006). "FDI and Spillover Effects in the Indian Pharmaceutical Industry", Research and Information System for the NonAligned and other Developing Countries, Discussion Paper \# 113, New Delhi: 1-44 (August).

[3] Blomström, Magnus, Steven Globerman,Ari Kokko (1999). "The determinants of Host Country Spillovers from Foreign Direct Investments: Review and Synthesis of the Literature". The European Institute of Japanese Studies, Stockholm School of Economics, Working paper \# 76.

[4] Budget (2007-08). Ministry of finance, Government of India, New Delhi www.india.budget.nic.in.

[5] Chaudhuri, S. (2005). "The WTO and India's Pharmaceutical Industry; patent protection, TRIPs and Development Counties", Oxford University Press, New Delhi: 133-134.

[6] CMIE (2010). "Foreign Trade and BOPs", Centre for Monitoring Indian Economy Pvt. Ltd., Mumbai

[7] Department of Pharmaceutical (2009), Annual Report 2009-10, Ministry of Chemical and fertilizers, Government of India. New Delhi.

[8] Department of Pharmaceutical (2009), Ministry of Chemical and fertilizers, Government of India, New Delhi, www. pharma. nic.in.

[9] Dhar, Biswajit and Niranjan Rao (2002). "Transfer technology for successful integration into the global economy: A Case study of the Indian pharmaceutical industry", UNCTAD, Working paper \# 22, United Nations, New York and Geneva.

[10] DIPP (2012). "FDI fact sheet", http://dipp.nic.in/English/Publications/FDI_Statistics/FDI_Statistics.aspx

[11] Directory of pharmaceutical manufacturing units in India (2007), National Pharmaceutical Pricing Authority, Government of India, New Delhi. http://www.nppaindia.nic.in.

[12] DOP (2009). Annual Report. Ministry of Commerce and Industry, Government of India, New Delhi.

[13] Dunning, J. (1970). "Studies in International Investments", The Pitman Press Bath, George Allen and Unwin Ltd.

[14] Ernst \& Young (2010). "Doing Business in India", Ernst \&Yong Pvt Ltd, Kolkata: 45-46. www.ey.com/india.

[15] Hathi committee (1975). "Report of the committee on Drugs and Pharmaceuticals Industry", Ministry of Petroleum and Chemical, New Delhi: 86-91.

[16] IBEF (2010)."Pharmaceuticals", Indian Brand Equity Foundation. www.ibef.org (April).

[17] ICRA Ltd. (2004).”Industry Watch: The Indian Pharmaceutical Industry”, Information and credit Rating Agency, New Delhi.

[18] Iyer, Parvathi. K. (2008). "Structure and Performance of Small and Medium Scale Pharmaceutical Firms", S\&T and Industry, India, Science and Technology:11

[19] Jha, Ravinder (2007). "Options for Indian Pharmaceutical Industry in the Changing Environment", Economic and Political Weekly, Sameeksha Trust Publication, Mumbai, XLII (39): 3958-3967 (Mumbai).

[20] Markusen, JR and AJ Venables (1997). "Foreign Direct Investment as a Catalyst for Industrial Development", National Bureau of Economic Research, 1050 Massachusetts Avenue, Cambridge.

National Pharmaceutical Policy (2006), Department of Chemical and Petrochemicals, Government of India, 2005, Part A (28 ${ }^{\text {th }}$ December). Pharmaceutical Policy (2002), Government of India, New Delhi.

Pharmaxil (2009), $6^{\text {th }}$ Annual Report, 2009-10: 8.

World Bank (1997). "Malaysia Enterprise Training, Technology and Productivity", A world bank Country Study, Washington DC.

World Investment report (1999). "FDI and the Challenges of Development", UNCTAD, New York. 